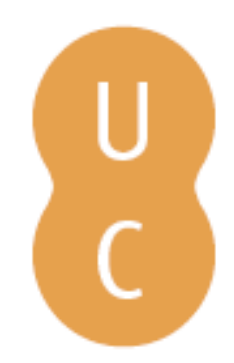

\title{
pommalina
}

\section{Apício como opus medicinale na Itália do Século XV: estudo de caso a partir de três manuscritos fiorentinos}

\author{
Autor(es): $\quad$ Nadler, Wanessa Asfora \\ Publicado por: Imprensa da Universidade de Coimbra \\ URL \\ persistente: URI:http://hdl.handle.net/10316.2/45229 \\ DOI: $\quad$ DOI:https://doi.org/10.14195/978-989-26-1721-3_2 \\ Accessed : $\quad$ 26-Apr-2023 14:19:34
}

A navegação consulta e descarregamento dos títulos inseridos nas Bibliotecas Digitais UC Digitalis, UC Pombalina e UC Impactum, pressupõem a aceitação plena e sem reservas dos Termos e Condições de Uso destas Bibliotecas Digitais, disponíveis em https://digitalis.uc.pt/pt-pt/termos.

Conforme exposto nos referidos Termos e Condições de Uso, o descarregamento de títulos de acesso restrito requer uma licença válida de autorização devendo o utilizador aceder ao(s) documento(s) a partir de um endereço de IP da instituição detentora da supramencionada licença.

Ao utilizador é apenas permitido o descarregamento para uso pessoal, pelo que o emprego do(s) título(s) descarregado(s) para outro fim, designadamente comercial, carece de autorização do respetivo autor ou editor da obra.

Na medida em que todas as obras da UC Digitalis se encontram protegidas pelo Código do Direito de Autor e Direitos Conexos e demais legislação aplicável, toda a cópia, parcial ou total, deste documento, nos casos em que é legalmente admitida, deverá conter ou fazer-se acompanhar por este aviso.

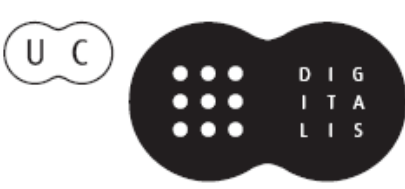


Carmen Soares

Gilene da Silva Gomes Ribeiro

(coords.)

\section{Mesas \\ LUSO-BRASILEIRAS}

\section{ALIMENTAÇÃO, SAÚdE \& GULTURA}

\section{VOLUME I}

IMPRENSA DA UNIVERSIDADE DE COIMBRA COIMBRA UNIVERSITY PRESS

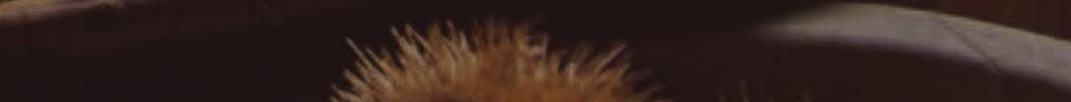




\title{
Apício como opUS MEDICINALE NA ItTália do \\ Século XV: estudo de CAso a PARTir de TRÊS MANUSCRITOS FIORENTINOS
}

\author{
(Apicius as opus medicinale in $15^{\text {th }}$-Century Italy: \\ case study of three Florentine manuscripts)
}

\author{
Wanessa Asfora Nadler \\ Projeto DIAITA: Património Alimentar da Lusofonia \\ (wanessaasfora@usp.br)
}

Resumo: O livro de cozinha de Apício, comumente chamado De re coquinaria, é muito provavelmente o mais famoso dos textos de cozinha que nos herdou a Antiguidade Latina. No entanto, apesar de tal celebridade, aspetos relacionados às particularidades de seus vários contextos de produção, redes de circulação e consumo permanecem objeto de pouca atenção da parte dos historiadores. Este artigo concentra-se em um momento específico da história dos textos apicianos, o Renascimento. Apresenta sua tradição manuscrita e, a partir do estudo de caso de três manuscritos fiorentinos, sugere conexões entre o conteúdo apiciano e a agenda de interesses de um grupo de humanistas fiorentinos do final do século XV.

Palavras-chave: Apício, Renascimento, alimentação, Medicina, livro de receitas, manuscritos.

Aвstract: The cookbook attributed to Apicius, traditionally known as De re coquinaria, is probably the best known text of all historical cookbooks. However, and despite its celebrity status, a variety of details concerning the copies that were made in different contexts of production, circulation and consumption still require further attention from historians. This paper is centered in one specific moment of the history of the Apician texts, the Renaissance. It presents their manuscript tradition and, based on the case study of three Florentine manuscripts, suggests connections between the content of the cookbook and the agenda of a particular group of Florentine humanists by the last decade of the $15^{\text {th }}$ century.

Keywords: Apicius, Renaissance, food, Medicine, cookbooks, manuscripts. 
As questões alimentares estão no centro das preocupações do homem contemporâneo. Seja do ponto de vista da medicalização, seja do ponto de vista da "gastronomização" (para usar um termo inexistente na Língua Portuguesa, mas que traduz a participação igualmente hiperbólica dos assuntos gastronômicos em nosso tempo), nunca se falou tanto em comida como atualmente ${ }^{1}$. Nesse cenário, o livro de cozinha atribuído a Apício, comumente chamado De re coquinaria, tem emergido, dentro e fora dos meios acadêmicos, como uma espécie de autorictas do mundo antigo que carregaria em si a semente do que se constituiria futuramente como o paradigma da arte de cozinha ocidental desenvolvida entre os séculos XVII e XIX. Uma espécie de pai da gastronomia "avant la lettre".

No entanto, o que se percebe é que às ideias que envolvem o nome de Apício não correspondem um conhecimento apropriado da história de seus textos e respectivos contextos de produção, circulação e consumo. O sentido de Apício no passado é certamente distinto daquele que o homem do século XXI lhe atribui. Se na atualidade ele pode ser facilmente posicionado ao lado da gastronomia e longe dos assuntos médico-dietéticos, por muito tempo essa aproximação não foi tão óbvia.

Este artigo é, justamente, um exercício de reflexão sobre a historicidade de Apício. Sua investigação não está centrada apenas no estudo do texto apiciano, mas igualmente na história da sua tradição manuscrita e dos atores com ela envolvidos. A partir de três manuscritos - São Petersburgo, Ist. Istor. Akad. Nauk, 627/1; Cidade do Vaticano, Biblioteca Apostolica Vaticana, Vat. Lat. 6337 e Munique, Bayerische Staatsbibliothek, Monacensi Latini 756 -, pretendo perseguir a hipótese de que a existência do interesse por Apício (e, consequentemente, da confecção de seus manuscritos) explica-se, em grande parte, pelas possibilidades que seu conteúdo suscitava dentro da agenda do humanismo médico fiorentino da segunda metade do século $\mathrm{XV}^{2}$.

\section{i. A tradição teXtual de Apício e os manuscritos renascentistas}

A atribuição de Apício como autor da coletânea de receitas modernamente conhecida como De re coquinaria nunca foi confirmada. É uma ação frequente encontrar o nome do romano Marco Gávio Apício (século I) associado ao texto, embora até hoje nenhuma evidência para sustentar tal afirmação tenha

1 Scholliers 2009.

${ }^{2}$ Este artigo é fruto do projeto de pesquisa de pós-doutoramento em curso junto ao Departamento de História da Universidade Estadual de Campinas e que conta com apoio financeiro da Fundação de Amparo à Pesquisa do Estado de São Paulo (FAPESP). Mais particularmente, apresenta informações e algumas reflexões possibilitadas pelo estágio de pesquisa desenvolvido no Centro de Estudos do Renascimento Italiano da Universidade de Harvard (Villa I Tatti) em Florença ao longo do ano de 2015. 
sido localizada. Sendo assim, a posição mais razoável a se assumir é considerar o texto como resultado de um processo anônimo e complexo de recolha de receitas iniciado no século II a. C. e finalizado por volta do século IV. É por esse motivo, inclusive, que os mais recentes editores do texto optaram por chamá-lo simplesmente 'A pício' e não pelo célebre título, efetivamente nunca encontrado em nenhum dos manuscritos existentes ${ }^{3}$. Opção que assumo por me parecer muito mais satisfatória do ponto de vista científico.

São dois os textos apicianos que se conhece. O mais longo, considerado texto canônico, abriga 459 receitas distribuídas ao longo de dez livros; já o mais curto contém 31 receitas organizadas em uma lista única (os Excerpta). A edição do texto canônico teve início no século XV e são encontradas edições feitas no séculos XVI e XVIII ${ }^{4}$. Entretanto, será apenas com as edições do século XIX, que pela primeira vez incluirão os Excerpta, que se disponibilizará elementos para o estabelecimento da moderna erudição sobre Apício ${ }^{5}$.

Os três manuscritos mais antigos de Apício são produto da Alta Idade Média latina. O primeiro deles, Paris, B.N.F. Lat. 10318 (A), que contém os Excerpta, tem datação e origem bastante discutíveis. Especialistas sugerem que tenha sido produzido em alguma localidade do sul da França ou do norte da Itália, possivelmente entre o final do século VIII e o início do século IX ${ }^{6}$. $\mathrm{O}$ texto canônico encontra-se em dois outros manuscritos, ambos bastante ligados ao contexto do chamado Renascimento Carolíngio: Nova Iorque, New York Academy of Medicine 1 (E), originário da abadia de Fulda e datado da primeira metade do século $\mathrm{IX}^{7}$ e Cidade do Vaticano, Biblioteca Vaticana Urb. Lat, 1146 (V) produzido na igreja colegial de Saint Martin de Tours, provavelmente entre os anos de 830 e $853^{8}$.

Até o momento, nada se conhece sobre a história dos manuscritos apicianos entre os séculos IX e XV. A primeira notícia sobre Apício aparecerá apenas em 1431, quando o humanista fiorentino Niccolò Niccoli (13651437), em seu Commentarium, menciona-o entre as obras a serem procuradas em mosteiros da Alemanha e da França pelos cardeais Niccolò Albergati e

${ }^{3}$ Grainger, Grocock 2006: 13-17.

4 Rothmagensem 1498; Venetum 1500; Tridino 1503; Torinus 1541; Hummelberg 1542; Lister 1709; Bernhold, 1787.

5 Schuch 1867; Ihm 1908; Giarratano 1912; Giarratano; Vollmer 1958; André 1969; Grainger, Grocock 2006. Uma lista atualizada de todas as edições e traduções de Apício foi publicada por Grainger, Grocock 2006: 120-123.

6 B.N.F Lat.10318; Wickersheimer 1966: 99-100; Milham 1967: 259-320; Munk-Olsen 1982: 8; Spallone 1982: 1-71; Grainger, Grocock 2006: 32-35; 116.

7 Academy of Medicine 1; Lowe 1920: 1174-1176; Milham 1967: 261-280; Munk-Olsen 1982: 3-4; Laurioux 1994: 25; Grainger, Grocock 2006: 118; Mayo 2008: 111-135.

8 Biblioteca Apostolica Vaticana, Urb. Lat. 1146; Stornatolo 1921: 174; Rand 1929: 144; Milham 1967: 64-265; Munk-Olsen 1982: 3-4; Buoncore 1998: 186-188. 
Giuliano Cesarini, então em missão diplomática para o Concílio de Basiléia9 . No entanto, Apicius acabou sendo encontrado apenas alguns anos depois por Alberto Enoch d'Ascoli que, seguindo as sugestões de Niccoli, adquiriu um dos manuscritos carolíngios na abadia de Fulda (E) em 1455.

Ascoli havia partido para o norte da Europa a pedido do papa humanista Nicolau V que em 1451 estava às voltas com a organização do acervo da biblioteca papa ${ }^{10}$. Sua missão era adquirir textos clássicos (manuscritos originais ou cópias) considerados essenciais ao modelo de biblioteca universal concebido pelo papa ${ }^{11}$. Quando Ascoli retorna à Itália em 1455 com os manuscritos que havia conseguido adquirir na viagem, encontra Nicolau V moribundo (ou possivelmente já morto) ${ }^{12}$. Seu sucessor, Calixto III, não era um humanista e não tinha interesse em dar continuidade ao projeto da biblioteca papal. Ascoli tenta, então, vender os manuscritos a humanistas ou senhores de famílias importantes da Itália que estavam naquele momento construindo suas bibliotecas privadas. Contudo, não foi fácil encontrar compradores que estivessem dispostos a pagar a quantia de 200 ou 300 florins por manuscritos que foram inicialmente considerados mais interessantes por sua novidade do que por sua utilidade. Pelo menos, é essa a impressão deixada por Carlo de' Medici (1428/30-1492) em uma carta escrita por ele a Giovanni de' Medici (1421-1463) em 13 de março de 1456:

[...] Egli è vero che $\mathrm{m}$. Enoche ha portato qui certe cose nuove, come vedrete per questo inventario vi mando ed invero da farne più stima per la novità che per la utilità. Lui pe insino a qui non ha volute farne

${ }^{9}$ Niccoli 1971. Aparentemente, a lista de texto de Niccoli foi escrita com base em informações compiladas pelo célebre humanista e caçador de obras antigas Poggio Bracciolini. Ainda hoje, discute-se se o manuscrito de Apício mencionado corresponde ao manuscrito carolíngio encontrado anos depois no mosteiro de Fulda por Ascoli (E). Para acompanhar o debate, cf.: Sabadini 1927: 45; Campana 1954: 211; Milham 1967: 263; Reynolds, Wilson 1991: 137; Laurioux 1994.

${ }_{10}$ A viagem de quatro anos foi especialmente motivada pela busca de um Tito Lívio mais completo. No itinerário estavam Dinamarca, Noruega, Alemanha e provavelmente outros lugares, embora não se tenha informação suficiente para precisá-los (por muito tempo, Enoch deixou de enviar notícias de seu paradeiro). Poggio não confiava na capacidade de Enoch, e acreditava que a viagem não traria resultados satisfatórios ("Ille enim Enoch adeo solers et diligens fuit, ut ne verbum quidem ad me adbuc scripserit - Itque parum spero illum aliquid boni facturum, nisi eum magis fortuna faverit, quam prudential et industria perquirendi" - Poggius, Epist. X, 17 del gennaio (1452 o 1453) apud Voigt 1968: 193).

11 Antes de tornar-se papa, Nicolau V, então Tommaso Parentucelli, compôs, a pedido de Cosimo I, o chamado Cânone Bibliográfico, documento que definia a lista de obras que deveria conter qualquer biblioteca que pretendesse seguir os valores do humanismo italiano de então - ideal que inspirou a organização das bibliotecas públicas do convento de São Marco, da Badia de Fiesole, e mais tarde, da própria Biblioteca Vaticana (Piccolomini, 1875; Pintor 1960; Ullman, Stadter 1972: 16; Manfredi 1994: xli; Manfredi 1998).

12 Se antes ou depois da morte do papa em 24 de março daquele ano é ainda motivo de discussão (Milham 1967: 263). 
copia a persona, imperò dice non vuole avere durate fatiche per altri e non delibera darne copia alcuna, se prima da qualche grande maestro no è remunerato degnamente ed ha oppenione d'averne almanco 200 o 300 fiorini, sì che vedete se volete gettare via tanti danari per cose che la lingua latina può molto bene fare senza esse, che a dirvi l'oppenione di molti dotti uomini, che gli ànno visti, da questi quattro infuori che sono segnati con questo segno $\mathrm{X}$, tutto il resto non vale una frulla $[\ldots]^{13}$.

$\mathrm{Na}$ verdade, sabe-se muito pouco sobre o destino de $\mathrm{E}$ no século XV. Alguns anos após a correspondência mencionada anteriormente, por volta de 1460, é possível que ele, ou uma cópia, tenha servido de base para a produção de pelo menos dois dos manuscritos renascentistas ${ }^{14}$. Na década de 1470 , fazia parte do acervo da biblioteca pessoal do Cardeal Bessarione (1403-1472) que, muito provavelmente, o deixou como herança, juntamente com outros volumes, a seu secretário Niccolò Perrotti (1430-1480) ${ }^{15}$. Posteriormente, talvez após a morte de Perrotti, o manuscrito passou às mãos de Francisco Maturanzio (1443-1518). Essas informações, fornecidas pelo colofão de um dos manuscritos renascentistas que será estudado um pouco mais adiante, resumem o que se conhece sobre a história do manuscrito no século XV. No século XVI, Apício parece ter ido parar na França onde, certamente no século XVIII, foi separado dos dois outros textos encadernados com ele (o texto hipocrático De observantia ciborum e o receituário médico anônimo que darão origem ao manuscrito Genebra, Bodmer Library, Cod. 84). Em cerca de 1820, os manuscritos são adquiridos por Sir Thomas Phillips, e no final da década de 1920, seu herdeiro Thomas Fitzroy Fenwick, venderá Apicius à estudiosa Margareth Wilson que, finalmente o doará à Biblioteca da Academia de Medicina de Nova York, onde se encontra atualmente ${ }^{16}$.

O outro manuscrito carolíngio de Apício (V) possui uma história bem mais obscura. Não existe informação sobre sua trajetória de Tours para a Itália onde aparecerá, pela primeira vez, mencionado no inventário da biblioteca dos Duques de Urbino compilado entre 1482 e $1487^{17}$. Antes disso, sabe-se apenas que uma cópia sua $(\zeta)$ já existia na Itália por volta de 1458 e que foi através dela que $V$ tornou-se o ancestral de todos os dezesseis manuscritos renascentistas de Apício produzidos na segunda metade do século $\mathrm{XV}^{18}$. Em

13 Archivio di Stato, M.A.P. Filza 9: 135; Milham 1967: 291.

14 Milham 1967: 265-274.

15 Bianca 1980: 103-165.

16 Mayo 2008: 124-132.

17 "Apicius Celius de condimentis. Codex vestustus. In purpureo" (apud Sabadini 1927: 47); Mayo 2008: 111-135.

18 Milham 1967: 263-267. 
$1658, \mathrm{~V}$, juntamente com outros manuscritos dos Urbino, entrará definitivamente para o acervo da Biblioteca Vaticana ${ }^{19}$.

O principal e, ainda hoje, mais importante estudo filológico sobre a tradição textual de Apício foi publicado em 1967 por Mary Ella Milham ${ }^{20}$. Neste trabalho, Milham propõe um stemma que organiza dezoito manuscritos apicianos (dois medievais - os Excerpta não foram considerados - e os dezesseis quatrocentistas), estuda a fortuna desses ao longo do Renascimento, bem como introduz alguns aspectos da relação entre a tradição manuscrita e o aparecimento das primeiras edições de Apício na Itália e no norte da Europa. O trabalho de Milham, juntamente com uma nova consulta dos manuscritos, constituem a base para a apresentação dos dezasseis manuscritos na Tabela 1 , organizada segundo a ordem de seu aparecimento no stemma de Milham ${ }^{21}$.

\begin{tabular}{|c|c|c|c|}
\hline \multicolumn{2}{|r|}{ REFERENCIA } & DATA & $\begin{array}{c}\text { ORIGEM/ } \\
\text { PROVENIENCIA }\end{array}$ \\
\hline 1 & $\begin{array}{c}\text { Florença, Biblioteca Medicea Laurenziana, } \\
\text { Plut. 73, } 20 \text { (L) }\end{array}$ & c. $1458-1464$ & Florença \\
\hline 2 & $\begin{array}{c}\text { Florença, Biblioteca Medicea Laurenziana, } \\
\text { Strozzi } 67(\mathrm{~S})\end{array}$ & $\begin{array}{l}\text { s. XV (segunda } \\
\text { metade) }\end{array}$ & Florença \\
\hline 3 & $\begin{array}{c}\text { Florença, Biblioteca Riccardiana, Ricc. } 141 \\
\text { (C) }\end{array}$ & $\begin{array}{l}\text { s. XV (segunda } \\
\text { metade) }\end{array}$ & Florença \\
\hline 4 & Florença, Biblioteca Riccardiana 662 (R) & 1464 & Florença \\
\hline 5 & $\begin{array}{c}\text { Cidade do Vaticano, Biblioteca Apostolica } \\
\text { Vaticana, Urb. Lat. } 1145(\mathrm{~T})\end{array}$ & $\begin{array}{l}\text { s. XV century } \\
\text { (após 1462-1464) }\end{array}$ & $\begin{array}{l}\text { Urbino, } \\
\text { provavelmente }\end{array}$ \\
\hline 6 & $\begin{array}{l}\text { Oxford, Bodleian Library, Bodleianus Add. } \\
\qquad \text { B } 110 \text { (B) }\end{array}$ & $\begin{array}{l}\text { s. XV (segunda } \\
\text { metade) }\end{array}$ & $\begin{array}{c}\text { Roma, } \\
\text { provavelmente }\end{array}$ \\
\hline 7 & $\begin{array}{c}\text { Cidade do Vaticano, Biblioteca Apostolica } \\
\text { Vaticana, Vat. Lat } 6803(\mathrm{~J})\end{array}$ & $\begin{array}{l}\text { s. XV (segunda } \\
\text { metade) }\end{array}$ & $?$ \\
\hline 8 & $\begin{array}{l}\text { Paris, Bibliothèque Nationale de France, Bnf, } \\
\text { Lat. } 8209(\mathrm{P})\end{array}$ & $\begin{array}{l}\text { s. XV (segunda } \\
\text { metade) }\end{array}$ & $\begin{array}{c}\text { Roma, } \\
\text { provavelmente }\end{array}$ \\
\hline 9 & Copenhagen, G1. Kgl. Sammlung 3553 (K) & 1479 & $\begin{array}{l}\text { Veneza, } \\
\text { provavelmente }\end{array}$ \\
\hline
\end{tabular}

19 Stornatolo 1921.

20 Milham 1967: 263. Em 2004, um manuscrito de Apício presente em um códice do século XVI foi recenseado na base de dados Manus (Cesimento dei manoscritti delle biblioteche italiane): Biblioteca Estense Universitaria, Estense, Lat. 134 = alfa.R.9.5 (http://manus.iccu. sbn.it//opac_SchedaScheda.php?ID=166461). O texto está em fragmentos e ainda não foi propriamente estudado em relação aos demais manuscritos do corpus apiciano.

${ }^{21}$ Os manuscritos L, S, C, R, T, J, G, Qe N foram consultados in loco; K, M, D, B e P foram acessados através de digitalizações. A serem verificados, permanecem Pol e $\mathrm{O}$. 
Apício como opus medicinale na Itália do Século XV: estudo de caso a partir de três manuscritos fiorentinos

\begin{tabular}{|c|c|c|c|}
\hline 10 & $\begin{array}{c}\text { Cesena, Biblioteca Malatestiana, } \\
\text { Malatestianus 167, 154 (G) }\end{array}$ & $\begin{array}{c}\text { s. XV (segunda } \\
\text { metade) }\end{array}$ & $\begin{array}{c}\text { Cesena, } \\
\text { provavelmente }\end{array}$ \\
\hline 11 & $\begin{array}{c}\text { São Petesburgo, Instituta Istorii Akademii } \\
\text { Nauk 627/2 (O) }\end{array}$ & $\begin{array}{c}\text { s. XV century } \\
\text { (após 1490-1493) }\end{array}$ & ? \\
\hline 12 & $\begin{array}{c}\text { Cidade do Vaticano, Biblioteca Apostolica } \\
\text { Vaticana, Vat. Lat. 8086 (Q) }\end{array}$ & $1483-1489$ & Bolonha \\
\hline 13 & $\begin{array}{c}\text { Oxford, Bodleian Library, Bodleianus } \\
\text { Canonicianus Class. Lat. 168 (D) }\end{array}$ & 1490 & Florença \\
\hline 14 & $\begin{array}{c}\text { São Petesburgo, Instituta Istorii Akademii } \\
\text { Nauk 627/1 (Pol) }\end{array}$ & $1490-1493$ & Florença \\
\hline 15 & $\begin{array}{c}\text { Cidade do Vaticano, Biblioteca Apostolica } \\
\text { Vaticana, Vat. Lat. 6337 (N) }\end{array}$ & 1494 & Florença \\
\hline 16 & $\begin{array}{c}\text { Munique, Bayerische Statsbibliothek, Stifs } \\
\text { clm 756 (M) }\end{array}$ & 1495 & \\
\hline
\end{tabular}

Tabela 1: Os dezasseis manuscritos renascentistas de Apício

Do conjunto de manuscritos apicianos, aqueles estudados neste artigo não foram escolhidos arbitrariamente. Existem aspectos da sua história que certamente podem auxiliar à compreensão acerca da natureza do interesse em um texto como Apício por parte de um grupo de humanistas da segunda metade do século XV. São eles:

1. São Petersburgo, Inst. Istor. Akad. Nauk, 627/2 (Pol). 9 ff; papel; 207x282mm; sem decoração; apenas Apício em fragmentos (iniciados ao final do livro VII). O códice é parte do acervo do Instituto Histórico da Academia de Ciências da Rússia. Possui dois colofões ao final do texto (f.9r) que nos permitem saber que esse exemplar de Apício foi ditado por Angelo Poliziano (1454-1494) a seu discípulo Piero Matteo Uberti entre os anos de 1490 e 1493:

Primeiro colofão: Contulit hunc Politianus librum cum vestuto ip(s)o exemplarj/unde emanasse caetera putantur quod e Germania avectum/ Enoch Pontifici Nicolao.V. dono dedit: indeq(ue) ad Bessarione(m)/ Cardinalem Nicenu(m), mox ad Nicolaum Perottum Episcopum/ Sipontinum; postremo ad Franciscum Maturantium p(er)venit./ Eiusq(ue) Politiano [mihi] Facta copia e(st) Alfeni Severi Perusini opera/ Sic aut(em) pro istituto suo contulit Politianus ut nihil/ hic ab exemplarij codex variet. xvii K(a)1(endas) Maias Anno M.CCCC. LXXXX. hora Ferme diei xxij, adiutoribus/Laurentio Cyatho (et) Petro Matheo uberto Familiarib(us)/ suius in suburbano Laurentij Medicis iunioris ad arni/ ripam. 
Segundo colofão: Iterum contuli: cum vestutissimo altero codice: de Urbinatis Ducis Guidonis/ biblioteca: signu(m) q(ue) hoc apposui 0: quoties alicubi a prioribus variasset: Anno Sal. Mcccclxxxxiij. Quarto nonas decembres/hora nocti tertia et $1 \frac{1}{2} \mathrm{i}(\mathrm{n})$ Pauli./ Idem Politianus ${ }^{22}$.

2. Cidade do Vaticano, Biblioteca Apostolica Vaticana, Vat. Lat. 6337 (N). 179ff; papel; 214×279mm; sem decoração; ff.1-39 Apício. Códice datável do final do século XV (mas o texto de Apício está datado 1494). O conteúdo do códice está organizado em três seções distintas: a primeira corresponde ao texto apiciano (f.1-38); a segunda é uma coleção que reúne textos de medicina ginecológica de autores diversos da antiguidade, o herbário de Pseudo-Apuleio e algumas receitas médicas (f.40r-160r); a terceira, finalmente, é outra coletânea médica com obras cuja temática comum é a propriedade de medicamentos feitos a partir de ervas e animais (a exemplo de De herba vettonica de Antônio Musa e Liber medicina ex animalibus de Sexto Plácido) e uma epístola de Hipócrates (161r-180v). A análise do colofão ao final do texto mostrou que esse texto de Apício foi copiado diretamente de Pol. De fato, a inscrição é a mesma, exceto pela data, 1494, e pelo nome do copista, um certo Lorenzo di Pier Lorenzi. As duas outras seções foram transcritas a partir de manuscritos médicos carolíngios dos séculos IX e X que hoje estão na Biblioteca Laurenziana ${ }^{23}$ : Contulit hunc Laurentianus libru(m) $\mathrm{cu}(\mathrm{m})$ vestuto ip(s)o exemplari unde emanasse caetera putantur quod e Germania avectu(m) Enoch pontifici Nicolao. V. dono dedit / indeq(ue) ad Bessarione(m) cardinale $(\mathrm{m}) \mathrm{Nicenu}(\mathrm{m})$ postremo. / Sic aut $(\mathrm{em})$ pro instituto suo contulit Laurentianus / ut nihil hic ab exemplari códex variet. / Iter(um) contuli cu(m) vestutissimo altero codice de Urbinatis ducis Guidonis biblioteca signu(m) q(ue) hoc adposui aqui tem um sinal / quotie(n)s alicubi a prioribus variasset. Anno / salutatis MCCCCLXXXXIIII. xi $\mathrm{k}(\mathrm{a}) 1$ (endas) martias hora / noctis tertia. / Idem Laurentius ${ }^{24}$.

${ }^{22}$ Inst. Istor. Akad. Nauk 627/1, f.9r apud Milham, p. 286.

${ }^{23}$ A segunda seção foi transcrita por um copista anônimo a partir de Florença, Biblioteca Medicea Laurenziana, Plut. 73.1. Para alguns estudiosos, é bastante provável que o comitente da cópia tenha sido o mesmo Lorenzo di Pier Lorenzi. Os textos da terceira seção foram selecionados e transcritos a partir de Florença, Biblioteca Medicea Laurenziana, Plut. 73.41 pelo já mencionado Pier Matteo Uberti e pelo próprio Poliziano. Do conjunto do códice, apenas esta terceira parte foi de fato encontrada na biblioteca de Poliziano (Campana 1954: 195; Maier, 1965: 359, Perosa 1980: 80; Beccaria 1956: 227-284).

24 Biblioteca Apostólica Vaticana, Vat. Lat. 6337: 39r. 
3. Munique, Bayerische Staatsbibliothek, Monacensi Latini 756 (M). 185 ff; papel; sem decoração; 220x295mm; ff.21-46 Apício. O códice é datável entre os anos de 1494 e 1500, porém Apício, graças ao colofão que aparece ao final do texto, pode ser datado 1495. Além da data de composição, a inscrição nos permite saber também que Piero Crinito foi o copista de Apício e de quase todo o restante do códice, exceto pelos fólios 166-177, onde se reconheceu a mão de Angelo Poliziano, mestre de Crinito.

Pet(rus) Crinit(us) Flor(en)tinus MCCCCLXXXXV. Martis. Transcripsi / aut(em) hunc n(ost)rum ab exemplari Ang. Politia(ni) p(rae)ceptoris, que $(\mathrm{m})$ ipse diligentissime eme $(\mathrm{n}) \mathrm{da} /$ verat $\mathrm{cu}(\mathrm{m})$ codice alio Nicoli $\mathrm{P}(\mathrm{e})$ rotti, tu $(\mathrm{m})$ ex aliis. Nos ferme om(n)ia servavimus ut / exemplaris typo quidem haud ungue lati(us) discesseri $(m)^{25}$.

O conteúdo do códice compreende três seções. A primeira (ff.5-20v) contém uma seleção de textos médicos, dentre eles o herbário do pseudo-Apuleio, extratos de textos ginecológicos, bem como algumas receitas médicas. Foi transcrita a partir do mesmo manuscrito carolíngio pertencente à coleção da Biblioteca Laurenziana usado como base para a segunda seção de N (Pluteo 73.1). A segunda seção (ff.21r-165) reúne Apício com textos de retórica de Consulto Fortunaciano, Agostinho e Júlio Severiano, panegíricos latinos e algumas fábulas de Esopo e Aviano (em excertos). Finalmente, na terceira seção (166r-185), encontram-se textos de autores cristãos como Venâncio Fortunato, Paulino de Nola, Beda, Arátor e Próspero da Aquitânia.

\begin{tabular}{|c|c|}
\hline & Conteúdo \\
\hline $\begin{array}{c}\text { Inst. Istor. Akad. Nauk, } \\
627 / 2 \\
(\text { Pol })\end{array}$ & Apício (f.123r-179v) \\
\hline $\begin{array}{c}\text { Vat. Lat. 6337 } \\
\text { (N) }\end{array}$ & \\
& I. \\
& [f.39-38 - Apício \\
\hline
\end{tabular}

\footnotetext{
25 Bayerische Staatsbibliothek, Monacensi Latini 756: 46r.
} 


\begin{tabular}{|c|c|}
\hline & 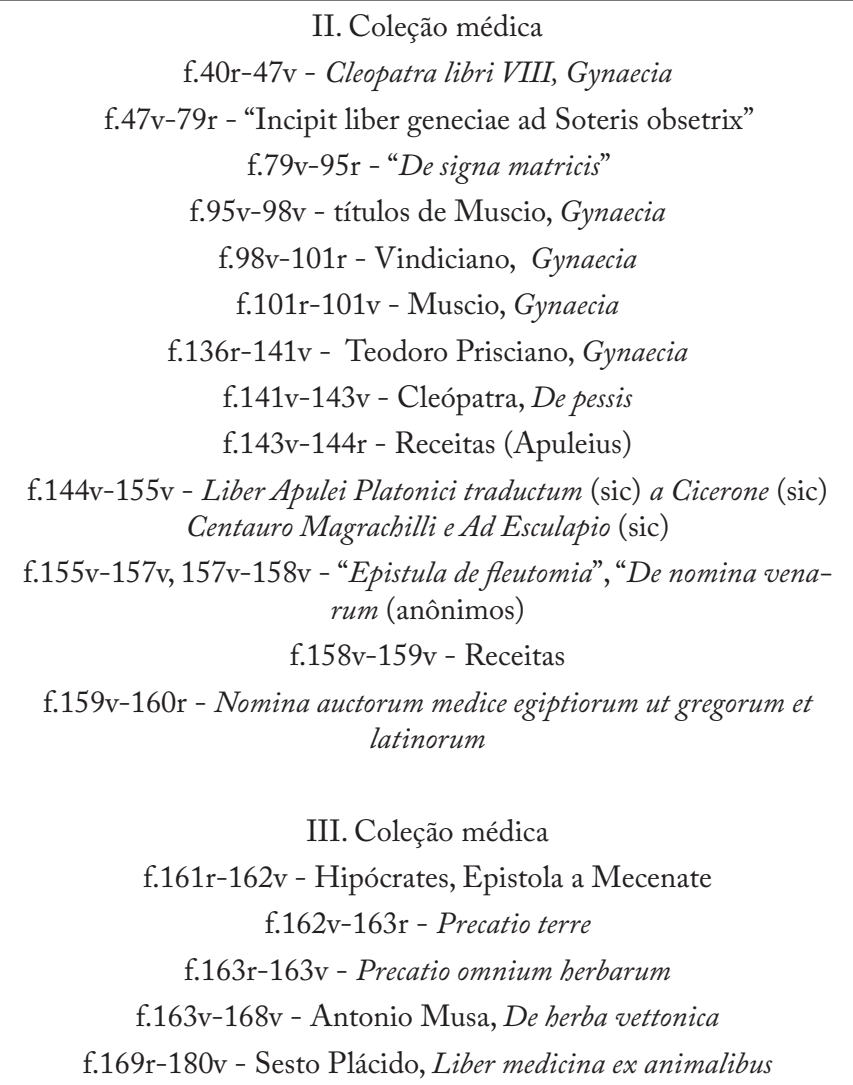 \\
\hline $\begin{array}{c}\text { Monacensi Latini } 756 \\
\text { (M) }\end{array}$ & $\begin{array}{c}\text { I. Coleção médica } \\
\text { f.5r-13v - Apuleio, Liber Apulej Platonici traditus a chyrone centauro } \\
\text { magistro achillis Aesculapio } \\
\text { f.14r-14v - Cleópatra, Excerpta e libris VI Cleopatrae de morbis } \\
\text { mulierum } \\
\text { f.15r-17v - Vindiciano, Excerpta } \\
\text { f.17v-18v - Muscio, Excerpta } \\
\text { f.18v-19r - Teodoro, Excerpta e Theodoro ad Sabinam } \\
\text { f.20r - Nomina auctorum medicinae egyptiorum ut graecorum latinoru- } \\
\text { mque }\end{array}$ \\
\hline
\end{tabular}


Apício como opus medicinale na Itália do Século XV: estudo de caso a partir de três manuscritos fiorentinos

\begin{tabular}{|c|c|}
\hline II. \\
f.21r-46r - Apício \\
[f.46v em branco] \\
f.47r-54v - Marco Júnio Nipso, De mensuris ad Celsum libri IL \\
f.55r-62r - Sexto Julio Frontino, De mensuris \\
[f.62v em branco] \\
f.63r-80v - Fortunaciano, Rhetorices libri III \\
f.80v-86r - Agostinho, Principia rhetoricae \\
[f.86v em branco] \\
f.87r-93r - Júlio Severiano, Praecepta artis rhetoricae summatim collecta \\
de multis aesytomatis \\
f.94r-150v- Panegírcios latinos, Panegyrici X \\
f.151r-165v - Esopo, Fabularum libri IV \\
III. \\
f.166r-170r - Venâncio Fortunato, Excerpta \\
f.171r-177r - Paulino de Nola, Excerpta \\
[f.177v em branco] \\
f.178r-180v - Beda, De arte metrica liber \\
f.181r - Arátor, Excerpta \\
f.184r-184r - Ávito de Viena, Excerpta \\
\end{tabular}

Tabela 2: Conteúdo dos códices de Apício

\section{Apí́cio COMO OPUS MEdicinale}

Um dos elementos comuns a dois dos códices apresentados é a existência de textos médicos encadernados juntamente com o texto apiciano. Para perseguir a lógica que permitiu reunir esses textos em um mesmo códice seria necessário saber exatamente quando tais textos, ou seções, foram reunidos. Infelizmente, dispõe-se de poucas informações nesse sentido. Sabe-se apenas que o códice onde está $M$ ganhou a configuração atual pelas mãos do próprio Crinito ainda no final do século $\mathrm{XV}^{26}$, e que o códice vaticano teria sido composto pelas mãos de algum fiorentino no século $\mathrm{XVI}^{27}$. Com isso, a relação dialógica entre o texto apiciano e os demais textos limitar-se-ia, de forma mais segura, a dados extra-códices, ou seja, contextuais.

Se fosse possível posicionar cronologicamente todos os manuscritos e edições apicianos e observá-los de longe, veríamos que, tanto antes quanto

\footnotetext{
${ }^{26}$ Marchiaro 2013: 201-215.

27 Campana 1954: 196.
} 
depois do século XV, a aproximação entre Apício e textos médicos não é um dado isolado. Em primeiro lugar, porque essa aproximação pode ser constatada no século IX em um dos manuscritos medievais existentes (E). Como já mencionado, nesse caso, Apício esteve encadernado em um mesmo códice com De observantia ciborum atribuída a Hipócrate ${ }^{28} \mathrm{e}$ um receituário médico anônimo (Genebra, Bodmer Library, Cod. 84). Em segundo lugar, porque esse mesmo tipo de aproximação entre Apício e textos médicos é constatada ainda no século XVI, quando se observa que a edição de Apício publicada em Lyon e Basel em 1541 apresenta no mesmo volume De tuenda valetudine, natura rerum et popine scientia libri $X$ ( = De honesta voluptate et valetudine $)$ de Platina e De facultatibus alimentorum de Paulo de Égina (c. 625-c. 690); e a edição de 1542 publicada em Zurich é organizada e comentada pelo médico Gabriel Hummelberg ${ }^{29}$.

Diante disso, seria possível falar na existência de uma tradição de avizinhamento de Apício e textos médicos? Ou ainda, mais diretamente, no entendimento de Apício como "opus medicinale"? A questão pode causar estranheza; no entanto, tem origem em uma passagem do humanista Niccolò Niccoli que em seu Commentarium - documento já mencionado que serviu como guia para a expedição livresca de Enoch d'Ascoli - assim descreve Apício: "In monasterio suldulensi [Fulda] continentur infrascripti libri... Aepitii de compositionis libri octo. opus medicinale et optimum"30.

A passagem foi inúmeras vezes citadas na bibliografia referente a Apício; porém, curiosamente, teve pouca (ou nenhuma) repercussão. Quando muito, a discussão sobre ela recaiu sobre a insólita e inexata descrição de Apício em 8 livros e não em 10; o que revelaria uma imprecisão ou desconhecimento da parte de Niccoli em relação ao verdadeiro texto apiciano. O fato de Apício ser adjetivado como obra medicinal, porém, requer reflexão, sobretudo porque enreda, de maneira instigante, texto e contexto da produção manuscrita. Pelo menos, no caso dos três manuscritos aqui estudados, os atores com eles

28 Trata-se da versão latina de Regimen II (também intitulado De victus ratione ou Peri enypnion). O texto pertence à coleção hipocrática e foi escrito, aparentemente, por volta de 400 a.C. Para os especialistas, Regimen II é o segundo de um conjunto de livros cujos temas abordados versam sobre a natureza humana (livro I), propriedades naturais e artificiais dos elementos do regime - comida, bebida, banho, sexo, sono, trabalho e exercício (livro II), as relações entre alimentação e exercício (livro III) e prognósticos por meio dos sonhos (livro IV). Aparentemente, esses quatro textos foram concebidos para formar um todo com De natura hominis (Mazzini 1984).

29 Seria possível estender essa cronologia e incluir em tal tradição as duas únicas edições do século XVIII, organizadas e comentadas por médicos, respectivamente por Martin Lister, médico da rainha Ana da Inglaterra (publicada nos anos de 1702 e 1709) e Joannes Michael Bernhold, médico e marquês de Brandenburgo (1787).

${ }^{30}$ Nova York, Morgan Library, M.497: 268v-270r apud De la Mare 1973: 45; Niccoli 1971. 
envolvidos foram todos humanistas que nutriram, direta ou indiretamente, interesse por textos médicos antigos.

Começo por Lorenzo di Pier Lorenzi (1459/60-1502) - conhecido também como Lorenzo Lorenzi ou também Lorenzo Laurentianus - a pessoa que assina o colofão do manuscrito N. Lorenzo era médico e ensinou, dentre outras disciplinas, medicina teórica e prática no Studio de Pisa durante os anos de 1479 e 1501 . Dedicou parte de sua vida à elaboração de novas traduções de antigos textos hipocráticos e galênicos. Do projeto de traduzir todo o corpus de Hipócrates e Galeno, conhece-se a tradução para apenas cinco obras. De Hipócrates, os Aforismos (datada 16 outubro de 1494) e Prognosticon, ambas com comentários de Galeno. De Galeno, De crisibus (terminada entre novembro e dezembro de 1494 e publicada em 1522 em Bolonha); Ars Medica (dedicada em 13 de fevereiro de 1500 a Francesco Pandolfini e publicada em Pavia em 1506 e posteriormente inserida na recolha latina de Galeno) e De differentis febrium (publicada em Paris em 1512). Além disso, há as versões de In Hippocratis predictiones, publicada em Florença em 1508. Suas traduções gozaram de certa fortuna e foram reimpressas, com mais ou menos revisões, até $1570^{31}$.

Nota-se que a cópia de Apício encontrada em $\mathrm{N}$ foi levada a cabo justamente no mesmo momento em que Lorenzo Lorenzi dedicava-se às traduções dos textos de Hipócrates e Galeno. Entretanto, tem-se sugerido que Lorenzo não tenha cotejado nenhum manuscrito mais antigo de Apício para fazer a sua cópia, como a inscrição do colofão sugere, mas que tenha plagiado a cópia já existente de Apício feita por Angelo Poliziano (Pol). Com isso, os especialistas colocam em dúvida até mesmo a originalidade das traduções de Lorenzo para os textos médicos antigos que podem ter sido igualmente plagiados da produção de Poliziano ${ }^{32}$.

Chama atenção, sem adentrar em tal polêmica, o fato de que, assim como Lorenzo, Poliziano também estava bastante envolvido com o projeto de tradução de textos médicos gregos desde a década de 1480. Exemplo disso são as anotações marginais feitas por ele em códices de Galeno ${ }^{33}$ e

31 Dorez 1907: 237; Fortuna 1999: 486; Palumbo 2006.

32 Perosa 1980. Uma posição mais mediada e reconhecedora dos méritos de Lorenzo pode ser encontrada em Verde 1973-1996: 1123-1124. Para desdobramentos mais recentes do debate, ver: Fortuna 1999 e Savino 2013.

33 O primeiro, Florença Biblioteca Medicea Laurenziana, Plut. 75,17, é um códice grego que contém alguns capítulos sobre matéria medica, seguidos por De compositione medicamentorum secundum locos de Galeno, repleto de comentários feitos pelo próprio Poliziano. Pertenceu à biblioteca do médico e astrônomo Paolo Dal Pozzo Toscanelli que o deixou, após sua morte em 1482, como herança ao amigo Poliziano. O momento em que foi estudado e comentado por Poliziano não pode ser precisado, uma vez que a inscrição deixada por ele aparece incompleta por motivos de má conservação. Os outros códices também foram herdados de Toscanelli: o segundo, Florença, Biblioteca Medicea Laurenziana, Plut. 28,37, contém os Phaenomena de 
a as referências a médicos da Antiguidade, como Paulo de Égina, Celso e Oribásio, citados ou discutidos em sua Miscellaneorum Centuria Secunda ${ }^{34}$. Além disso, Poliziano mantinha contato frequente com médicos de seu tempo envolvidos com traduções de textos de medicina grega. Pier Leoni da Spoleto (c. 1445-1492), médico de Lorenzo de' Medici e professor de medicina no Studio de Pisa (e ali colega de Lorenzo Lorenzi), possuía uma biblioteca rica em volumes médicos antigos a qual Poliziano teve oportunidade de fazer algumas incursões. Foi a ele também que Poliziano pediu, em carta escrita em 1490, que fizesse a revisão de sua tradução dos Aforismos (da qual não restou nenhum manuscrito) $)^{35}$. Na mesma época, ainda, trocou correspondência com o ilustre médico de Ferrara, Niccolò Leoniceno (1428-1524), acerca de algumas questões de nomenclatura científica sobre a qual já falarei mais adiante.

Tanto para Poliziano quanto para Lorenzi, o projeto de tradução dos textos gregos de Hipócrates e Galeno foi interrompido com a morte de ambos, nos anos de 1494 e 1502, respectivamente. No caso de Poliziano, Pietro Crinito (1474-1507), seu discípulo, encarregou-se da organização de alguns de seus escritos, dentre eles a cópia e reunião dos textos que compõe o zibaldone onde está o manuscrito M de Apício ${ }^{36}$. Crinito, como Poliziano, não era médico de profissão, mas parece ter tido em algum momento de sua vida certo interesse pela medicina antiga, frequentando, inclusive, um curso sobre Hipócrates ministrado pelo próprio Lorenzo Lorenzi no Studio de $\mathrm{Pisa}^{37}$. Interesse que talvez tenha sido bastante pontual ou não tenha deixado muitos traços, uma vez que em sua obra enciclopédica, De honesta disciplina, há pouquíssimas referências à medicina e nenhuma a Apício $^{38}$. Contudo, a relação de familiaridade entre Crinito e Lorenzi é atestada por inscrições que indicam a colaboração de ambos para confecção de alguns trabalhos de

Arátor; e o terceiro, Florença, Biblioteca Medicea Laurenziana, Plut. 75,8, além de vários fragmentos de escritos médicos de Aécio e Dioscórides, possui uma outra cópia de De compositione medicamentorum de Galeno. Neste último, a inscrição permite saber que foi consultado em 1487.

34 Poliziano 1972.

35 "Vorrei che V. M. intendessi, se maestro Pier Leone volessi durar fatica in rivedere quella mia traduzione di Ippocrate e Galieno, che è quasi al fine, e così el commento che fa sopra, dove dichiaro tutti e termini medicinali che vengono dal greco, e truovo come si possino chiamare latine. Se la Sua Eccelenza volessi durar fatica, poi al tempo la manderei fuori più arditamente; che stimo sarà bella cosa et utile, se l'amor non me inganna. Messer Ermolao e l'Conte mostrono pur d'averne buona opinione." (Poliziano 1867: 77).

${ }_{36}$ Palumbo 2006; Campana 1954: 208; Billanovich 1962: 137; Di Piero 1910: 3; Marchiaro 2013: 15-18.

37 "Quod etiam mox Laurentiano florentino contigit, cuius ego academiam aliquando accessi eiusque disciplinae auditor interfui, cum Aristotelis opera atque Hippocratis commentarios magna eruditione exponeret." (Crinito 1955: 113).

${ }^{38}$ De Crinito restam poucas obras conhecidas. Além de De honesta disciplina, publicou ainda De poetis e os Poemata (Crinito 1955). 
cópia de textos ${ }^{39}$, bem como por referências a Lorenzi deixadas pelo próprio Crinito em De honesta disciplina. É Crinito que nos conta, por exemplo, sobre as conversas eruditas mantidas entre ele, Lorenzi, Savonarola (1384-1468) e Pico della Mirandola (1463-1494) ${ }^{40}$.

A esse ponto, convém perguntar qual seria propriamente a relação entre o interesse por textos médicos gregos antigos e Apício. Para o filólogo italiano Alessandro Perosa, a resposta é simples: Apício era um autor caro aos interessados em matéria médica - Poliziano, dentre eles - uma vez que existia uma clara afinidade entre culinária e dietética ${ }^{41}$. Juliana Hill Cotton, que dedicou justamente um artigo aos interesses de Poliziano pela materia medica, é da mesma opinião ${ }^{42}$. A sugestão desses estudiosos é instigante, mas, sem dúvida, merece uma melhor investigação e reflexão, a começar pelo fato de que tecnicamente Apício não poderia ser classificado como texto farmacológico a exemplo de De materia medica de Dioscórides, tão pouco um texto dietético, como os regimes ${ }^{43}$.

Como foi recentemente demonstrado, durante a Antiguidade e, possivelmente a Alta Idade Média, parte das receitas apicianas ofereciam conselhos terapêuticos possíveis de serem postos em prática (das 459 receitas do texto canônico, 13 apresentam recomendações cuja finalidade é claramente terapêutica $\left.^{44}\right)$. A esse grupo, seria possível ainda adicionar receitas sem recomendações diretas, porém contendo ingredientes com especificidades médicas a exemplo daquelas que fazem uso de garum e seus derivados, vinho e seus derivados, além de compostos à base de sal e especiarias ${ }^{45}$. Contudo, o contexto histórico e cultural da segunda metade do século XV é bastante diverso e o corpus dietético de então não parece ter sido influenciado pelo texto apiciano de forma alguma ${ }^{46}$. Além disso, mesmo que o tivesse, seria preciso resolver um problema central: o garum, ingrediente presente em cerca de $90 \%$ das receitas apicianas, teria praticamente desaparecido das cozinhas europeias após a Alta Idade, tornando impraticável o livro de cozinha apiciano ${ }^{47}$.

39 Marchiaro 2013: 15-18.

40 Crinito 1955: III, cap. 2 e V, cap. 1.

41 "[Apicio] autore caro ai cultori di materia medica, per le affinità esistenti tra culinária e dietética" (Perosa 1980: 79).

42 Cotton 1957: 242.

43 Agrimi, Crisciani 1994; Montero Cartelle 2010.

${ }^{44}$ De acordo com a edição de Grocock e Grainger, são essas as receitas: $1.27 ; 1.34 ; 3.2 .1$; 3.2.2; 3.2.3; 3.2.4; 3.6.1; 3.6.2; 3.6.3; 3.18.2; 9.10.12; 3.17 e 9.8.5.

${ }_{45}$ Kokoszko 2012.

46 A esse respeito, cf. a produção acadêmica sobre alimentação no final da Idade Média e Renascimento, particularmente os trabalhos de Allen Grieco (1992, 1996, 1998), Bruno Laurioux $(1992,1997,1998,2006)$ e Ken Albala (2002).

47 Curtis 1991: 184-190. 
Já a menção à materia medica é desafiadora porque nos faz pensar se Apício não teria um papel coadjuvante no estudo da farmacologia, estando de alguma forma à serviço da medicina dietética no período. Com efeito, desde a Idade Média, a matéria da farmacologia encontrava-se na natureza (grosso modo, na Physica $)^{48}$. O seu conhecimento podia ser acessado a partir de diferentes pontos de partida como o estudo dos campos (agronomia) ou o estudo das plantas, animais e minerais (botânica, zoologia e mineralogia). Embora na segunda metade do século XV essas fronteiras disciplinares permanecessem irreconhecíveis enquanto tais, o momento acolhe algumas perspectivas, ainda um tanto quanto diversas e pontuais, de aproximação com o mundo natural que, no limite, configurará o que se entende hoje por história natural.

No centro-norte da Itália, especificamente, humanistas e médicos humanistas ${ }^{49}$ preocupam-se cada vez mais em fazer uma descrição mais acurada do mundo natural. Problemáticas como a precisão de nomes e atributos de plantas, animais e minerais começam a integrar a sua agenda; exemplo disso é o debate que ficou conhecido na historiografia como "Erros de Plínio" e que se desenrola contemporaneamente à confecção dos três manuscritos apicianos aqui estudados. Basicamente, a discussão gira em torno da má leitura que Plínio teria feito de suas fontes botânicas gregas, dentre elas Teofrasto e Dioscórides. A sua História Natural, portanto, apresentaria incongruências no reconhecimento de espécies vegetais e em traduções que poderiam gerar problemas para a prática médica, uma vez que não exporiam de maneira correta, dentre outras coisas, as propriedades medicinais das plantas. No debate, vários humanistas posicionam-se ao lado de Plínio, dentre eles Poliziano, Pico della Mirandola e Pandolfo Collenuccio (1444-1504) que escreve em 1483 uma Pliniana defensio. O principal crítico de Plínio foi Niccolò Leoniceno - cujos escritos compostos ao longo de vinte anos serão reunidos em quatro artigos publicados sob o título De Plinii et plurium aliorum medicorum in medicina erroribus apenas em $1509^{50}-\mathrm{e}$, de modo um tanto ambíguo, o médico Ermolao Barbaro (1454-1493), que apresentou seu ataque em Castigationes plinianae $(1493)^{51}$.

${ }^{48}$ Gauvaud, Libera, Zink 2002: 967-976; Glick, Livesey, Wallis 2005: v. II, 359-364.

49 Os termos humanismo médico e medicina humanística, já usados inicialmente por Walter Pagel, foram introduzidos no estudo da história da medicina em 1979 por Jerome Bylebel, especificamente para designar as atividades encabeçadas por Niccolò Leoniceno em Ferrara (The School of Padua: Humanistic medicine in the Sixteenth Century). De lá para cá, novas edições e traduções de textos médicos produzidos no âmbito do Renascimento, bem como estudos sobre determinados aspectos da medicina desse período têm contribuído para a compreensão dos aportes e limites da utilização dessas categorias. Para uma breve síntese sobre o assunto, cf. Presenti 1999.

50 Leoniceno 1509. Nota-se que os escritos de Leoniceno não foram dirigidos apenas a Plínio, mas também a outros médicos.

51 Especificamente sobre a discussão botânica do debate, ver Greene 1983: v. 2, 531-543; Thorndike 1960: 593-594; Castiglioni 1953. 
Parece-me importante reforçar que discussões filológicas como aquelas que circundaram os debates sobre os Erros de Plínio ou sobre a tradução dos Aforismos de Hipócrates comentados por Galeno, mencionados neste artigo, possuíam um caráter a um só tempo estético e prático. Algo que, de alguma maneira, caracterizava os últimos anos do século XV quando o interesse dos humanistas e de médicos humanistas iniciam a convergir. Não se tratava apenas da filologia pela filologia, do grego pelo grego, do latim pelo latim, mas igualmente da aquisição de um saber específico - parte do programa dos studia humanitatis - sobre a natureza e a medicina: "coisa bela e útil", na sintética formulação de Poliziano para explicar a Lorenzo de’ Medici o resultado de seu trabalho de tradução do texto hipocrático que proporia, além de tudo, a origem grega de termos médicos e sua sinonímia latina. Aspecto que não passara desapercebido e era, sem dúvida, aprovado por seus pares, como ele próprio fez questão de acrescentar ${ }^{52}$.

Observa-se que os três manuscritos de Apício são copiados em meio à intensa atividade intelectual no que concerne o estudo da medicina antiga, grega principalmente. A busca pelas teorias terapêuticas hipocráticas e galênicas em textos supostamente originais, sem a mediação dos manuscritos medievais latinos e árabes, levou os humanistas e médicos humanistas a se debruçarem na produção de novas traduções. Poliziano, Lorenzi e Crinito são testemunhas disso. Ao mesmo tempo, a história natural carecia ser melhor estudada, pois, justamente, ela é a matéria-prima da terapêutica médica no período. Não se pode esquecer que a dieta (em seu sentido lato) e, secundariamente, a administração de fármacos constituíam as duas vias principais para manutenção da saúde e cura de doenças ${ }^{53}$.

Há que se dizer, por fim, que ao examinar o conteúdo dos Aforismos $^{54}$ e de parte da literatura produzida no âmbito do debate sobre os Erros de Plínio ${ }^{55}$, não se encontrou, até o momento, nenhuma referência imediata a Apício. No entanto, no Panepistemon de Poliziano - obra escrita no mesmo período em que os manuscritos aqui estudados foram copiados e que propõe uma sistematização do conhecimento humano -, Apício é mencionado como texto posicionado no encontro de dois campos do saber, a cozinha e a medicina:

52 Para o texto da carta, cf. nota 35. No inventário de Pico, composto em 1498, existe a menção a um manuscrito de Apício em pergaminho (" $M$. Apitius C., 32, Picius in membr. ms/ numerus 360/ capsae 8) - dado ainda não suficientemente estudado pelos especialistas (Kibre 1966: 172).

53 Cook 1996: 91.

${ }^{54}$ Hipocrates 1931.

55 Leoniceno 1509. 
Coquinariae capita Graeca referam, qualia ponit Apitius. Ea sunt epimeles, artoptus (sic), cepurica, pandecter, osprion (sic), trophetes, polyteles, tetrapus, thalassa, halieus, hanc Plato adulatricem medicinae appelat. ${ }^{56}$

\section{Considerações finais}

Sendo assim, a reflexão sobre o que buscavam em Apício os humanistas da segunda metade do século XV deve passar, necessariamente, pela compreensão da maneira como era tecida a relação entre cozinha e medicina no período. De qualquer forma, permanece-se válida, no âmbito do recorte documental selecionado para este artigo, a hipótese de que o texto apiciano tivesse exercido papel coadjuvante para a constituição de um saber médico-farmacológico na Itália do final do século XV, mais especificamente no círculo fiorentino. Apício permitiria acessar o mundo natural - plantas e animais, principalmente - pelas lentes de uma antiga, e suspostamente não corrompida, autorictas. Poderia, igualmente, funcionar como uma espécie de glossário/elenco da natureza, assemelhando-se, de certa forma, à função desempenhada pela literatura produzida pelos escritores das rei rustica (Catão, Varrão, Columela e Paládio) que desde 1472, quando começaram a ser disponibilizados em edições conjuntas, ganharam enorme difusão e suscitaram grande interesse ${ }^{57}$.

\section{REFERÊNCIAS}

\section{Manuscritos}

Florença, Archivio di Stato, M.A.P. Filza 9: 135.

Genebra, Bodmer Library, Cod. 84, Disponível em: <http://www.e-codices.unifr.ch/en/ list/one/cb/0084>, Acesso em: 14 dez. 2015.

Paris, Bibliothèque Nationale de France, Lat. 10318, Disponível em: <http:// archivesetmanuscrits.bnf.fr/ead.html?id=FRBNFEAD000072049>, Acesso em: 14 dez. 2015.

Nova York, Academy of Medicine, Disponível em: <https://nyam.org/library/>.

Cidade do Vaticano, Biblioteca Apostolica Vaticana, Vat. Lat. 6337.

Cidade do Vaticano, Biblioteca Apostolica Vaticana, Urb. Lat. 1146, Disponível em: $<$ http://digi.vatlib.it/view/MSS_Urb.lat.1146/0001/thumbs?sid=bdaa0a70cb8c 0bd9824641d5f46f2c12\#current_page>, Acesso em: 14 dez. 2015.

Modena, Biblioteca Estense Universitaria, Lat.134=alfa.R.9.5.

\footnotetext{
56 Poliziano 1553: 469.

57 Scriptores 1472; Coturri 1968: 99.
} 
Apício como opus medicinale na Itália do Século XV: estudo de caso a partir de três manuscritos fiorentinos

Munique, Bayerische Staatsbibliothek, Monacensi Latini 756, Disponível em: <http:// daten.digitale-sammlungen.de/ db/0001/bsb00011556/images/index.html?id= 00011556\&groesser=\&fip=193.174.98.30\&no=\&seite=1 >, Acesso em: 14 dez . 2015.

São Petersburgo, Inst. Istor. Akad. Nauk 627/1.

\section{Fontes editadas}

André, J. (ed.) (1965), Apicius. L'art culinary, Belles Lettres, Paris, 1965.

Bernhold, J. M. (ed.) (1787), Caelii Apicii De opsonis et condimentis sive arte coquinaria libri $X$, Marcobraitae.

Crinito, P. (1955), De honesta disciplina, ed. Carlo Angeleri, Fratelli Bocca, Roma.

Flower, B., Rosembaum, E. (ed.) (1958), The Roman Cookery Book, London.

Giarratano, C. (ed.) (1912), I codici dei libri de re coquinaria di Celio, Napoli.

Giarratano, C., Vollmer, F. (ed.) (1922), Apici librorum x qui dicuntur de re coquinaria, Leipzig.

Grainger, S., Grock, C. (ed.) (2006), Apicius: a critical edition with an introduction and English translation of the Latin recipe text, Prospect Books, Totnes.

Ihm, M. (1908), "Die Apicius-Exzerpte im Codex Salmasianus”, Archiv für Lateinische Lexikographie und Grammatik xv: 63-73.

Hipócrates (1931), Aphorisms, Ed. e trad. W. H. S. Jones, Harvard University Press, Cambridge, Mass., v. 4.

Hummelberg, G. (ed.) (1542), Apicii Caelii De opsonis et condimentis sive arte coquinaria, libri $X, Z$ Zürich.

Leoniceno, N. (1509), De Plinii, et plurium aliorum medicorum in medicina erroribus opus primum, J. Maciochius, Ferrara.

Lister, M. (ed.) (1709), Apicii Caelii De opsonis et condimentis sive arte coquinaria, libri decem cum annotationibus, Amsterdam.

Milham, M. E. (ed.) (1969), Apicii decem libri qui dicuntur De re coquinaria, Teubner, Leipzig.

Niccoli, N. (1971), "Commentarium in peregrinatione Germaniae”, Ed. Remigio Sabbadini, Storia e critica dei testi latini, II, Antenore, Padova, 7-9.

Poliziano, A. (1553), Opera, Nicolaus Episcopus, Basel.

Poliziano, A. (1897), Prose volgari inedite. Poesie latine e greche edite e inedite. Ed. Isidoro del Lungo, G. Barberà, Firenze, 1897.

Poliziano, A. (1972), Miscellaneorum Centuria Secunda, Ed. Vittore Branca e Manlio Pastore Stocchi, Fratelli Alinari, Instituto di Edizioni Artistiche, Firenze, 4v.

Rothmagensem, G. S. (ed.) (1498), Appicius culinarius, Milano.

Schuch, C. T. (ed.) (1867), Apici Caeli de re coquinaria libri decem, Heidelberg. 
Scriptores rei rusticae, seu Cato, Varro, Columella, Palladius Rutilius Taurus (1472), curaverunt Georgius Merula [Alexandrinus] et Franciscus Colucia, Nicolaus Ienson, Venezia.

Torinus, A. (ed.) (1541), Caelii Apitii summi adulatricis medicinae artificis De re culinaria libri $X$, Basel.

Tridino, I. C. de (ed.) (1503), Apitii Celii de re coquinaria libri decem, Venezia.

Venetum, B. (ed.) (1500), Apitiii Celi de re coquinaria libri decem, Venezia.

\section{Obras de referência e estudos}

Agrimi, J., Crisciani, C. (1994), Les consiglia médicaux, Brepols, Turnhout.

Albala, K. (2002), Eating right in the Renaissance, UCLA Press, Berkeley.

Beccaria, A. (1956), I codici di medicina del periodo presalernitano, Edizioni di Storia e Letteratura, Roma.

Bianca, C. (1980), "La formazione della biblioteca latina del Bessarione", Scrittura, biblioteche e stampa a Roma nel Quattrocento, Città del Vaticano, 103-165.

Billanovich, G. (1962), "Il Petrarca e i retori latini minori”, Italia Medievale e Umanistica 5: 103-164.

Buoncore, M. (1998), Vedere i classici: l'illustrazione libraria dei testi antichi dall'età romana al tardo medioevo, Fratelli Palombi, Roma.

Campana, A. (1954), "Contributi alla bibliotheca del Poliziano, in Il Poliziano e il suo tempo: atti del IV Convegno internazionale di studi sul Rinascimento, Firenze, 23-26 settembre 1954, 184-217.

Castiglioni, A. (1953), "The School of Ferrara and the Controversy on Pliny", in E. Underwood, Science, Medicine and History, Oxford University Press, LondonNew York-Toronto, v. 1, 269-279.

Cook, H. (1996), "Physicians and natural history", in N. Jardine, J. Secord, E. Spary (eds.), Cultures of Natural History, Cambridge University Press, Cambridge, 91105.

Coturri, E. (1968), "Il ritrovamento di antichi testi di medicina”, Espisteme 2: 91-110.

Cotton, J. H. (1957), "Materia Medica del Poliziano", in Il Poliziano e il suo tempo: Atti del IV Convegno Internazionale di Studi sul Rinascimento Firenze 1954. Firenze, 237-246.

Curtis, R. (1991). Garum and salsamenta. Production and commerce in material medica, Brill, Leinden.

De La Mare, A. (1973), The Handwriting of Italian Humanists, Oxford University Press, Oxford, v. 1.

Di Pierro, C. (1910), “Zibaldoni autografi di Angelo Poliziano”, Giornale Storico della Letteratura Italiana 55: 1-32. 
Apício como opus medicinale na Itália do Século XV: estudo de caso a partir de três manuscritos fiorentinos

Dorez, L. (1907), Le portrait de L. L., Bulletin de la Société Française de Histoire de la Médecine 6: 235-238.

Ferrari, G. (1990), "Gli Errori di Plinio. Fonti classiche e medicina nel conflito tra Alessandro Benedetti e Nicolò Leoniceno", in A. Cristiani (ed.), Sapere elè potere. Discipline, Dispute e Professioni nell'Università Medievale e Moderna. Il caso bolognese a confronto. Atti del 4o Convegno. Bologna, 13-15 aprile 1989, v. II, verso un nuovo sistema del sapere, Istituto per la Storia di Bologna, Bologna, 173-204.

Fortuna, S. (1999), "Le prime traduzioni umanistiche degli aforismi di Ippocrate", in I. Garofalo (ed.), Aspetti della terapia nel Corpus Hippocraticum: Atti del IXe Colloque international hippocratique: Pisa, 25-29 settembre 1996. L. S. Olschki, Firenze, 485-498.

Gauvard, C., Libera, A., Zink, M. (ed.) (2002), Dictionnaire du Moyen Âge, Presses Universitaires de France, Paris, 2002.

Glick, T., Livesey, S., Wallis, F. (ed.) (2005), Medieval science, technology, and medicine: an encyclopedia, Routledge, London, v. 11.

Greene, E. (1983), Landmarks of Botanical History, Ed. F. Egerton, Stanford University Press, Stanford, v. 2.

Grieco, A. (1992), "From the cookbook to the table: a Florentine table and Italian recipes of the fourteenth and fifteenth centuries”, in C. Lambert (ed.), Du manuscrit à la table: Essais sur la cuisine au Moyen Âge, Presses Universitaires de Montréal/ Champion-Slatkine, Paris/Montreal, 29-38.

Grieco, A. (1998), “Alimentação e classes sociais no fim da Idade Média e na Renascença”, in J. L. Flandrin, M.Montanari (eds.), História da Alimentação, Estação Liberdade, São Paulo, 466-477 [1. ${ }^{\mathrm{a}}$ ed. 1996].

Grieco, A. (1996), “Cocina mediterránea o dieta mediterránea (del siglo XIV a pricípios del XVI)” in X. Medina (ed.), La Alimentación Mediterránea: historia, cultura, nutrición. Icária Antrazyt, Barcelona, 117-126.

Halm, K., Laubmann, G., Meyer, W. Catalogus Codicum Latinorum Bibliothecae Regiae Monacensis. Monachi, 1892, Disponível em: <http://daten.digitale-sammlungen. de/ db/bsb00008251/images/index.html?fip=193.174.98.30\&seite=198\&pdfse itexa>.

Kibre, P. (1966), The Library of Pico della Mirandola, AMS Press, New York, 1966.

Kokoszko, M., Rzeźnicka, Z., Jagusiak, K. (2012), “Health and Culinary Art in Antiquity and Early Byzantiumin the Light of De re Coquinaria”, Studia Ceranea 2: 145164.

Laurioux, B. (1994), Cuisinier à l'antique: Apicius au Moyen Âge, Médiévales, 26: 17-38.

Laurioux, B. (1992), Idade Média à mesa, Publicações Europa-América, Lisboa.

Laurioux, B. (1997), Les livres de cuisine médiéraux, Brepols, Turnhout, 1997 (Typologie des Sources du Moyen Âge Occidental, 77). 
Laurioux, B. (1998), "Cozinhas medievais (séculos XIV e XV)" in J. L. Flandrin, M. Montanari (ed.), História da alimentação, Estação Liberdade, São Paulo, 447-465.

Laurioux, B. (2006), Gastronomie, humanisme et societé à Romes au milieu du XVe siècle. Autour du De honesta voluptate de Platina. Sismel/Edizione del Galluzo, Firenze.

Lowe, E. (1920). "Die Haupthandschriften des Apicius", Berliner Philologische 40: 11741176.

Maier, I. (1965), Les manuscrits d'Ange Politien. Catalogue descriptif, Librairie Droz, Genève.

Manfredi, A. (1994), I codici latini di Niccolò V. Edizione degli inventari e identificazione dei manoscritto, Biblioteca Apostolica Vaticana, Città del Vaticano.

Manfredi, A. (1998), "The Vatican Library of Pope Nicholas V: the Project of a Universal Library in the age of Humanism", Library History 14: 103-110.

Marchiaro, M. (2013), La biblioteca di Piero Crinito. Manoscritti e libri a stampa della raccolta libraria di un umanista fiorentino, Porto.

Mayo, H. (2008), "New York Academy of Medicine MS 1 and the Textual Tradition of Apicius", Classica et Beneventana 36: 111-135.

Mazzini, I. (1984), De observantia ciborum: traduzione tardo-antica del Perì diaítes pseudoippocratico, Bretschneider, Roma.

Milham, M. E. (1967), "Toward a stemma and fortuna of Apicius", Italia medioevale e bumanistica 10: 259-320.

Montero Cartelle, E. (2010), Tipologia de la literatura médica latina. Antiguedad, Edad Media, Renacimiento, Féderation Internationale des Instituts d'Études Médiévales, Porto.

Munk-Olsen, B. (1982), L'étude des auteurs classiques latins aux XIe et XIIIe siècles, I. Catalogue des manuscrits classiques latins copies du IXe au XII siècle, Apicio-Juvenal, Paris.

Palumbo, M. (2006), "Lorenzo Lorenzi”, in Dizionario Biografico degli Italiani Treccani, v. 66, Disponível em: <http://www.treccani.it/enciclopedia/lorenzo-lorenzi_ (Dizionario_Biografico)>.

Perosa, A. (1980), "Codici di Galeno postillati dal Poliziano", in V. Branca et al. (ed.), Umanesimo e Rinascimento, Studi offerti a Paul Oskar Kristeller, Leo L. Olschki, Firenze, 75-109.

Piccolomini, E. (1875), Richerche alle condizione e alle vicende della Medicea private dal 1494 al 1508, Archivio Storico Italiano 21: 282-296.

Pintor, F. (1960), "Per la storia della libreria medicea nel Rinascimento. Appunti D'Archivio", Italia Medioevale e Umanistica 3: 188-210.

Presenti, T. (1999), "Annotazioni sull'umanesimo medico", Quaderni per la storia della Università di Padova 32: 249-259.

Rand, E. (1929), A Survey of the manuscripts of Tours, The Medieval Academy of America, Cambridge, Mass. 
Apício como opus medicinale na Itália do Século XV: estudo de caso a partir de três manuscritos fiorentinos

Reynolds, L., Wilson, N. (1991), Scribes and Scholars. A guide to the transmission of Greek and Latin Literature, Clarendon Press, Oxford [1. ${ }^{\mathrm{a}}$ ed. 1968].

Sabadini, R. (1927), "I codici di Apicio”, Historia I: 42-49.

Savino, C. (2013), "La traduzione di Lorenzo Lorenzi del Commento di Galeno agli Aforismi di Ippocrate: un caso di plagio?”, Medicina nei Secoli, 25/23: 1023-1062.

Scholliers, P. (2009), "O novo cenário da gastronomia”, in P. Freedman (org.), A história do sabor, Senac, São Paulo, 333-357.

Siraisi, N. (1997), The clock and the mirror. Girolamo Cardano and Renaissance Medicine, Princeton University Press, 1997.

Spallone, M. (1982), "Il Par. Lat. 10318 (Salmasiano): dal manoscritto alto-medievale ad una raccolta enciclopedica tardo-antica”, Italia Medioevale e Umanistica 25: 1-71.

Stornatolo, C. (1921), Codices Urbinatis Latinis, Roma, v. 3.

Thorndike, L. (1960), A bistory of magic and experimental Science, Columbia University Press, New York, v. 4.

Ullman, B., Stadter, P. (1972), The Public Library of Renaissance Florence, Antenore, Padova.

Verde, A. F. (1973-96), Lo Studio fiorentino 1473-1503, I-VI, Firenze 1973-1996.

Voigt, G. (1968), Il Rissorgimento dell'Antichità Classica ovvero Il primo secolo dell'Umanesimo, Trad. G. C. Sansoni, Firenze, v. 2 [1. ${ }^{\mathrm{a}}$ ed. 1890].

Wickersheimer, E. (1966), Les manuscrits latins de médicine du haut Moyen Âge dans le bibliothèques de France, Paris. 